\title{
Surgery for gastroesophageal reflux disease: a comparative study between the open and laparoscopic approaches
}

\author{
R. Trullenque Juan, T. Torres Sánchez, E. Martí Martínez, M. Martínez Abad, R. Trullenque Peris ${ }^{1}$ and \\ F. Delgado Gomis
}

Service of General Surgery. Hospital Dr. Peset. ${ }^{~}$ Hospital General. Valencia, Spain

\begin{abstract}
Objective: given the demonstrated effectiveness of medical treatment together with the eminent acceptance of the laparoscopic approach, the indications of surgery in the treatment of gastroesophageal reflux disease (GERD) are currently subject to continuous controversy. To participate in this debate, we have the following work hypothesis: "The results of the $360^{\circ}$ short and floppy laparoscopic fundoplication are superior to those of open surgery".

Clinical design: prospective, clinical, non-randomized study.

Patients: our work was developed between November 1991 and December 1998 by means of a prospective, non-randomized clinical rehearsal with two groups of patients:

-Group I ( $\mathrm{n}=75): 360^{\circ}$ short and floppy laparoscopic fundoplication in Hospital Dr. Peset, Valencia (Spain).

-Group II ( $n=28): 360^{\circ}$ short and floppy, open fundoplication in Hospital General, Valencia (Spain).

We evaluated the preoperative parameters and found no differences, which allows us to know that both groups were comparable.

Results: the analysis of peroperative results (morbidity and surgical time) and of clinical follow-up (every three months and later annually) and instrumental follow-up (TEGD, upper digestive endoscopy, pHmetry and manometry) show no differences, while the postoperative analysis shows statistically significant (s.s.) differences regarding recovery (pain, oral intake, hospital stay and return to previous activities).

Conclusions: the results of the $360^{\circ}$ short and floppy laparoscopic fundoplication are similar to those of the open approach, but favor the former approach with a better postoperative tolerance.
\end{abstract}

Key words: Gastroesophageal reflux disease. Laparoscopic surgery. Open surgery.
Trullenque Juan R, Torres Sánchez T, Martí Martínez E, Martínez Abad M, Trullenque Peris R, Delgado Gomis F. Surgery for gastroesophageal reflux disease: a comparative study between the open and laparoscopic approaches. Rev Esp Enferm Dig 2005; 97: 328-337.

\section{INTRODUCTION}

The appearance of laparoscopic surgery (LS) in modern surgery has represented an authentic revolution: it is now known to represent a smaller aggression for patients (1), which translates into better postoperative outcome (2) with less pain, shorter recovery time (3), and better cosmetic results.

At present there is some consensus on GERD: complementary explorations demonstrate the disease, medical treatment is very effective (4), and there is also agreement regarding the surgical technique to use. However, other topics remain: indications of surgery, technical details of fundoplication, and surgical approach.

To try and analyze these two approaches to GERD, our present work deals with the following objectives:

1. To demonstrate reflux through the study of changes unveiled by complementary explorations (radiological study, upper digestive endoscopy, 24-hour pHmetry, and manometry), and to structure two homogeneous groups of patients.

2. To compare both approaches: LS with a control group undergoing open surgery (OS) during the same period of time.

3. To compare short- and long-term results.

\section{MATERIAL AND METHODS}

Recibido: $12-11-03$

Aceptado: 22-12-04.

Correspondencia: Ramón Trullenque Juan. Servicio de Cirugía. Hospital Dr Peset. Avda. Gaspar Aguilar, 90.46017 Valencia. e-mail: ramtrull@yahoo.es
This is a prospective, non-randomized clinical study performed between November 1991 and December 1998 
in which we operated on patients with GERD who were candidates for surgery using $360^{\circ}$ short and floppy fundoplication (SFF); two groups of patients were made up:

-Group I: 75 patients subjected to LS by a 3-surgeon team specially devoted to gastroesophageal disease in Hospital Dr. Peset, Valencia.

-Group II: 28 patients undergoing OS by a team similar to that of group I in Hospital General, Valencia.

We designate as SFF a procedure in which the gastric fundus is wrapped around the abdominal esophagus in its entire circumference along 2 or 3 centimeters, which can be calibrated in an instrumental way (endoesophagic tutor or upper digestive endoscopy) or visually by the surgeon.

Cholecistectomy, as a surgery associated with FFS (5), was carried out in a similar way in both groups: 10 patients in group I and 2 patients in group II. In both groups, the number of stitches used for closing the diaphragmatic pillars was between 2 and 3, while those for the wrap were usually 3 . The valve was sutured to the right pillar in $15 \%$ of cases in group I, while in group II this fixation went to the esophagus in $100 \%$. A nasogastric tube was used for all patients in group II and $46 \%$ of patients in group I. A short-vessel (SV) section was carried out only for gastric valves showing too much tension, and was necessary for $11(14.6 \%)$ patients in group I and $8(28.5 \%)$ patients in group II. For valve calibration an endoesophagic tutor was used in $7 \%$ of cases in group I and $15 \%$ of cases in group II.

The indications for surgical treatment were identical in both groups (6):

-Absent or partial response to medical treatment (8 12 weeks)

-Patients with symptomatic control of GERD by means of an appropriate medical treatment, but with relapse upon treatment discontinuation or a desire to get rid of medical treatment.

- GERD complications: progression of the esophageal mucosal lesions (III-IV), stenosis after endoscopic dilation, esophageal ulcer, hemorrhage, and atypical manifestations.

For the statistical analysis we used the Chi-squared and Student's T tests. Regarding preoperative data, differences were not observed between groups.

\section{RESULTS}

1. During the operation: a conversion to OS was necessary on one occasion in group I due to a pneumothorax that interfered with mechanic ventilation. The average surgical duration in minutes was a bit superior in group I but without statistically significant (s.s.) differences: 146 versus $113.4 \mathrm{~min}$.

Peroperative morbidity was somewhat bigger in the OS group, with differences not reaching s.s. (14.2 versus $6.6 \%$ ). In group I, there were: a duodenal laceration in the course of one difficult cholecistectomy that was repaired by means of suture by LS, two neumothorax cases, a lac- eration of the right diaphragmatic pillar that forced the employment of a mesh, and a perforation in the gastroesophageal union due to the introduction of the endoesophagic tutor, which was repaired by means of a suture in two layers and FSS. In group II this was secondary to three splenic injuries that required splenectomy on two occasions and one splenorrhaphy.

2. In the immediate postoperative period: we analyzed comfort and postoperative recovery through: analgesic requirement (5 versus 9 doses), initiation of peristalsis (29.2 versus 39.4 hours), time to withdrawal of the nasogastric tube ( 34.8 versus $50.6 \mathrm{~h})$, time to oral intake (40 versus $52 \mathrm{~h}$ ), and postoperative hospital stay ( 5 versus 7.8 days). On the whole, we observed differences that were s.s. in favor of LS.

Mortality was nil in the two groups, while postoperative morbidity was greater -with s.s.- in the group undergoing OS (35.7 versus $18.7 \%$ ). In the open group, the following occurred: an abdominal hemorrhage that was treated by means of blood support, a hemothorax that required percutaneous drainage and blood support, 3 surgical wound complications (2 eviscerations and one hematoma), and 2 solid-induced dysphagia cases. In the LS group one abdominal hematoma that required blood supply, 2 wound complications (one seroma and one hematoma), 2 solid-induced dysphagia cases, and 3 subcutaneous emphysemas.

Return to normal activity was earlier in the group undergoing LS (s.s.). In this way home activity (assessed as the patient's capacity to care for him -or herself at home after hospital discharge) and labor activity were recovered after 7 days (3-13) and 25 days (15-36), respectively, in group I, and after 15 days (9-25) and 31 days (24$57)$ in group II.

3. Revision ( 1 year minimum and 8 years maximum): follow-up in both groups was superior to $85 \%$. We analyzed the subjective appreciation of surgery results using Visick's classification: in this way, between $94.6 \%$ and $100 \%$ of patients in group I were classified as having a good result (Visick I and II), while in group II this percentage was estimated between 66.6 and $100 \%$, with these differences lacking in value given the limited number of patients analyzed during the past 5 years. On analyzing satisfaction by asking patients whether they would undergo surgery again in case of having the same symptoms as before, s.s. differences were not seen (92\% in group I and $82.2 \%$ in group II would undergo surgery anew).

Also, we assessed symptoms of GERD relapse:

- Heartburn (three patients in group I, in whom treatment with proton pump inhibitors -PPIs- was necessary when re-operation was rejected, and two patients in group II undergoing re-operation).

-Regurgitation (no patient).

-Epigastric pain (three cases with moderate symptoms, two in group I and one in group II) (Table I).

The typical symptoms index reflected similar results in the two groups, with scores between 0 and 1 in $85-100 \%$ 
Table I. Clinical findings of recurrence: heartburn, regurgitation and epigastric pain (number of patients)

\begin{tabular}{|c|c|c|c|c|c|c|c|c|c|c|c|c|c|c|c|c|c|c|}
\hline \multirow[b]{2}{*}{ Groups } & \multicolumn{2}{|c|}{1 month } & \multicolumn{2}{|c|}{3 months } & \multicolumn{2}{|c|}{1 year } & \multicolumn{2}{|c|}{2 years } & \multicolumn{2}{|c|}{3 years } & \multicolumn{2}{|c|}{4 years } & \multicolumn{2}{|c|}{5 years } & \multicolumn{2}{|c|}{6 years } & \multicolumn{2}{|c|}{7 years } \\
\hline & 1 & II & 1 & II & 1 & II & 1 & II & 1 & II & 1 & II & 1 & II & 1 & II & 1 & II \\
\hline \multicolumn{19}{|l|}{ Heartburn } \\
\hline -Mild & 1 & - & 1 & 2 & 1 & - & 1 & - & - & - & - & - & - & - & - & - & - & - \\
\hline -Severe & - & - & - & - & 2 & 2 & 2 & 2 & 3 & 2 & 3 & 1 & 3 & 1 & - & 1 & - & 1 \\
\hline \multicolumn{19}{|l|}{ Epigastric pain } \\
\hline -Mild & - & - & - & - & 1 & - & 1 & - & 1 & - & 1 & - & - & - & - & - & - & - \\
\hline -Moderate & - & - & - & - & 1 & 1 & 1 & 1 & 2 & 1 & 1 & 1 & 1 & - & - & - & - & - \\
\hline Regurgitation & - & - & - & - & - & - & - & - & - & - & - & - & - & - & - & - & - & - \\
\hline
\end{tabular}

We describe the number of patients showing symptoms of GERD relapse according to severity and over time (clinical follow-up visits at 1 and 3 months, and subsequently every year) for the two groups in the study (group I: laparoscopic surgery; group II: open surgery).

of cases in group I and in 66-100\% in group II for all periods of follow-up.

Surgery side effects included: early dysphagia (assessed even if present once a week): 52 in group I and $46 \%$ in group II; late dysphagia: between 5 and $9 \%$ in group I and $3.6-7.1 \%$ in group II; meteorysm and gasbloat syndrome (1 moderate case in group I); vomiting and burping difficulties ( 5 severe cases in group I and 1 in group II), and early satiety (ES) (Table II).

In group I a readmission took place during follow-up due to dysphagia that required endoscopic dilation, while in group II readmissions occurred at two to 3 months for epigastric pain and an episode of upper digestive hemorrhage in which endoscopy revealed gastritis and a barium study the thoracic migration of the valve. These complications regressed with medical treatment.

In group I, we re-operated no patients; in group II, a second surgery was necessary for three cases, including: a total duodenal diversion for the clinical persistence of GERD in spite of medical treatment with full-dose PPIs after 3 years, an FSS with mesh placement for a suspect- ed gastric volvulus (upper digestive hemorrhage, epigastric pain and neurovegetative manifestations) in a hernia recurrence after 2 years, a Boerema's operation for an hernia recurrence and clinical persistence of GERD in spite of medical treatment with full-dose PPIs after 8 years.

Besides these, 5 ventral hernias were detected in group I that were repaired (no mesh required) with the help of local anesthesia and sedation; in group II 6 ventral hernias required general anesthesia and a mesh for repair.

The results of the functional study are summarized in tables III and IV:

-Barium study: in group I one thoracic migration of the gastric valve was detected after 2 years, and a wrap disruption was seen within the first year; both were associated with relapsed heartburn and treated with PPIs. In group II, on the other hand, two valve disruptions were seen during the second year that forced re-operation in spite of heartburn persistence.

-Upper endoscopy: it was carried out more commonly than usual in order to demonstrate our results, with all

Table II. Side effects after surgery (number of patients)

\begin{tabular}{|c|c|c|c|c|c|c|c|c|c|c|c|c|c|c|c|c|c|c|}
\hline \multirow[b]{2}{*}{ Groups } & \multicolumn{2}{|c|}{1 month } & \multicolumn{2}{|c|}{3 months } & \multicolumn{2}{|c|}{1 year } & \multicolumn{2}{|c|}{2 years } & \multicolumn{2}{|c|}{3 years } & \multicolumn{2}{|c|}{4 years } & \multicolumn{2}{|c|}{5 years } & \multicolumn{2}{|c|}{6 years } & \multicolumn{2}{|c|}{7 years } \\
\hline & 1 & II & 1 & /I & 1 & II & 1 & II & 1 & II & 1 & II & 1 & $\|$ & 1 & II & 1 & II \\
\hline \multicolumn{19}{|l|}{ Dysphagia } \\
\hline -Mild & 38 & 13 & 17 & 2 & 5 & 1 & 6 & 1 & 3 & 1 & 3 & 1 & 1 & - & - & - & - & - \\
\hline -Severe & 1 & - & 1 & - & - & - & - & - & - & - & - & - & - & - & - & - & - & - \\
\hline Early satiety & 3 & 3 & 3 & 1 & 2 & 1 & 1 & 1 & 1 & - & 1 & - & 1 & - & - & - & - & - \\
\hline Meteorism & 13 & - & 15 & - & 15 & - & 7 & 2 & 3 & 2 & 6 & 2 & 4 & 1 & - & - & - & - \\
\hline
\end{tabular}

\begin{tabular}{lcc} 
Other symptoms & \multicolumn{2}{c}{ Groups } \\
\cline { 2 - 3 } & \multicolumn{1}{c}{ I } & \multicolumn{1}{l}{} \\
\hline Gasbloat & 1 & - \\
Hindered vomiting and burping & 15 & 1 \\
Diarrhea & 2 & - \\
Hiccup & 1 & - \\
\hline
\end{tabular}

We describe the number of patients with clinical side effects after surgery over time (initially at 1 and 3 months, then once yearly) for the two groups in the study (group I: laparoscopic surgery; group II: open surgery). 
Table III. Results from the functional study (1): barium study and upper digestive endoscopy (in numbers of patients)

\begin{tabular}{lcccc}
\hline Barium study & \multicolumn{2}{c}{ Group I } & \multicolumn{2}{c}{ Group II } \\
\hline & $3 m$ & $12 m$ & $3 m$ & $12 m$ \\
\cline { 2 - 5 } Valve disruption (slipped hernia) & 0 & 1 & 0 & 0 \\
Paraesophageal hernia & 1 & 2 & 0 & 0 \\
Gastroesophageal reflux & 0 & 3 & 0 & 0 \\
Valve migration & 0 & 0 & 1 & 1 \\
Stenosis (emptying difficulties) & 6 & 2 & 0 & 0 \\
& & & & \\
Upper digestive endoscopy & & & & \\
Esophagitis is absent & 30 & 35 & 5 & 21 \\
Esophagitis degree I & 3 & 3 & 1 & 3 \\
Esophagitis degree II & 4 & 1 & 1 & 4 \\
Esophagitis degree III & 0 & - & - & - \\
Esophagitis degree IV & 1 & - & - & - \\
\hline
\end{tabular}

The results of upper digestive endoscopy and the barium study are described as seen at instrumental control visits at 3 months and 1 year after surgery in the two groups (group I: laparoscopic surgery; group II: open surgery).

Table IV. Results from the functional study (2): 24-hour manometry and pHmetry

\begin{tabular}{|c|c|c|c|c|}
\hline \multirow[t]{2}{*}{ 24-hour pHmetry } & \multicolumn{2}{|c|}{ Group I } & \multicolumn{2}{|c|}{ Group /I } \\
\hline & $3 m$ & $12 m$ & $3 m$ & $12 m$ \\
\hline$\%$ (percentage) of total time with $\mathrm{pH}<4$ & 2.09 & 2.74 & 4.75 & 2.82 \\
\hline$\%$ of time in supine position with $\mathrm{pH}<4$ & 1.79 & 2.15 & 3.57 & 3.24 \\
\hline$\%$ of time in standing position with $\mathrm{pH}<4$ & 1.84 & 2.4 & 1.5 & 3.48 \\
\hline $\mathrm{N}^{0}$ (number) of episodes with $\mathrm{pH}<4$ & 13.11 & 26.71 & 28.38 & 26.78 \\
\hline $\mathrm{N}^{0}$ of episodes $>5$ minutes in duration & 1 & 0.85 & 2.7 & 1.35 \\
\hline Time in minutes for the longest episode & 13.64 & 7.27 & 9.13 & 7.57 \\
\hline De Meester index & 7.51 & 8.06 & 9 & 9.08 \\
\hline \multicolumn{5}{|l|}{ 24-hour pHmanometry } \\
\hline Pressure of LES (mmHg) & 25.21 & 22.1 & 35.43 & 27.79 \\
\hline Length of LES (cm) & 4.28 & 4.42 & 5.13 & 4.83 \\
\hline
\end{tabular}

The results for 24-hour manometry and pHmetry are described as seen at the instrumental post-surgical control at three months and one year in the two groups (group I: laparoscopic surgery; group II: open surgery).

patients exhibiting mild or absent esophagitis within the first year.

-24-hour pHmetry: in group I this test was abnormal in $11.5 \%$ at months 3 and 12 , while in group II these results were 12.5 and $22 \%$, respectively.

-24-hour manometry: the pressure of LES was estimated in most cases superior to be above $15 \mathrm{mmHg}$ at months 3 and 12 after surgery: 88.2 and $75.4 \%$ for group I, 100 and $85.7 \%$ for group II.

\section{DISCUSSION}

The study of peroperative results in the literature yields some average operative times for LS that oscillate between 60 and 218 minutes, while these vary from 57 to
170 minutes for OS. Peroperative complications (7) in LS oscillate between 2 and $8 \%$, while in OS they are estimated between 4.7 (8) and $15.5 \%$ (9) at the expense of splenic lesions. Our experience is comparable to published results.

During the immediate postoperative period morbidity as contributed by the literature is estimated for LS to be between 2.3 and $14.5 \%$ (esophago-gastric perforation and thoracic migration of the gastric valve being typical), while it is between $17(3,4)$ and 22\% (10) for OS; in our experience it was a little above published results. In LS readmission is required in up to $2.6 \%$ of cases, and re-operation (for valve migration) in $1.6 \%$. Mortality in the literature oscillates between 0 and $0.4 \%$; our experience was nil.

In the immediate postoperative period hospital stay according to the literature is between $23 \mathrm{~h}$ and $5.4 \mathrm{~d}$ for $\mathrm{LS}$ versus $7.2 \mathrm{~d}$ and $15.2 \mathrm{~d}$ for OS, which means that LS is advantageous in this respect (11). This early hospital discharge (12) is followed by an earlier return to activity when compared to OS: home activity at 7-14 d for LS and 21-31 d for OS, and work at 14-41 d and 34-69 d, respectively. These data are consistent with those obtained in our work.

When analyzing the results of clinical follow-up, Visick classification scores as given by the literature (13) after LS show degrees of satisfaction I and II in 88-95\% (14) of patients, these figures being $67-93 \%$ for OS (15). Our results are consistent with these.

The effects of surgery on complementary explorations (16) show the following results:

- As regards postoperative pHmetry (17) a normalization of all parameters takes place during the first postoperative control (18), with up to $10 \%$ of pathological (19) pHmetry results, which represents a rate of instrumental recurrences higher than that of clinical recurrences (20). Our experience was similar.

- The manometric effects of FSS show (21): a restoration of normal LES pressure in its three aspects (baseline half pressure, abdominal length, and total length) $(18,22-$ 25). We demonstrated a s.s. increase in average LES pressure, whilst length remained unchanged. In our series cases with hypomotility of the esophageal body went back to normal in the postoperative period ( 5 in group I and 3 in group II).

- Barium studies detected defective gastric valves in up to $8 \%$ at 1 year and $30 \%$ at 10 years (26). Our results are in contrast to those published within the first year.

- Upper digestive endoscopy confirms the cure of esophagitis in 85 to $100 \%$ of cases within the first year, and in $83 \%$ of cases at 6 years (21). During follow-up we observed cure rates of $89 \%$ in group I and $75 \%$ in group II within the first year.

Regarding the control of typical GERD symptoms, those reported reflect (27):

- Heartburn: for LS between 0 and $12 \%$ within 3 years; for OS $(28,29)$, on the other hand, $10 \%$ (between 7 and $18 \%$ ) with a similar follow-up. 

cases.

- Regurgitation: it develops after surgery in $1-6 \%$ of

-Dysphagia (30): complementary explorations are useless to predict dysphagia; the only related factor is rather preoperative dysphagia (31). Two forms exist:

- Early: for LS in 10-90\%, with endoscopic dilation being required in $1-8 \%$ of cases.

- Persistent: for LS in $0.6-18 \%$; in $24 \%$ for OS (between 17 and $43 \%$ ).

These results are consistent with those obtained in our work.

Regarding the presentation of atypical (pulmonary and laryngeal) symptoms, effectiveness is less predictable, as these may develop in up to $14 \%$ of cases. In our experience (two patients in group I had pulmonary manifestations in an isolated way, it seemed) they were solved with surgery.

Surgery side effects reported by the literature include:

-Early satiety: in up to $49 \%$ of cases. In our study this symptom developed in a lower percentage.

-Inability to vomit: 25 and $70 \%$ of cases at 2 years' follow-up. Inability to burp is estimated to develop in 1520 to $60 \%$ of cases. Our results for the LS group are similar to those published.

Lastly, regarding re-operations, not all patients with symptoms are candidates for second surgery (in a series of 48 symptomatic patients only $65 \%$ were re-operated (32). Re-operation rates in LS oscillate between 0.5 and $10 \%$, and are frequently secondary to the thoracic migration of gastric valves. In our work, we re-operated no patients in the laparoscopy group, with relapse cases being controlled using medical treatment; in the open surgery group three patients were re-operated, though.

\section{CONCLUSION}

We conclude that the results of $360^{\circ}$ short and floppy fundoplication using a laparoscopic approach are similar to those of open surgery, with the former showing better postoperative tolerance and fewer abdominal wall complications, all this in association with an earlier return to usual activity.

\section{ADDENDUM}

At present, in our LS experience of FSS: a) we virtually use no nasogastric tubes; b) we use no endoesophageal tutor, but rather visually gauge the gastric valve; c) we do not fix the gastric valve; and d) we rarely dissect the SV.

\section{REFERENCES}

1. Carbonell Antolí C. Prólogo. In: Delgado Gomis F. Cirugía laparoscópica para cirujanos generales. Madrid: Acirhospe ed, 1995. p. 10-3.

2. Bolufer Cano JM, Delgado Gomis F. Respuesta biológica a la cirugía laparoscópica. In: Delgado Gomis F. Cirugía laparoscópica para cirujanos generales. Madrid: Acirhospe ed, 1995. p. 189-202.
3. Rey Moreno A, Martínez Ferriz A, Suescun García R, Espadas Padial B, Hernández Carmona J, Navarro Pinero A, Oliva Munoz H. Analysis of surgery of gastroesophageal reflux by laparotomy and laparoscopy approach. Rev Esp Enferm Dig 1996; 88: 247-51.

4. Moss SF, Armstrong D, Arnold R, Ferenci P, Fock KM, Holtmann G, et al. GERD 2003 - a consensus on the way ahead. Digestion 2003; 67: 111-7.

5. Pozo F, Giganto F, Rodrigo L. Non-complicated cholelithiasis associated with GERD. Results of combined laparoscopic surgery in low risk patients. Rev Esp Enferm Dig 2004; 96: 237-45.

6. Mattioli S, Lugaresi ML, Pierluigi M, Di Simone MP, D’Ovidio F. Review article: indications for anti-reflux surgery in gastro-oesophageal reflux disease. Aliment Pharmacol Ther. 2003; 17 (Supl. 2): 60-7.

7. Watson DI, De Beaux AC. Complications of laparoscopic antireflux surgery. Surg Endosc 2001; 15: 344-52.

8. Urschel JD. Complications of antireflux surgery. Am J Surg 1993 ; 166: 68-70.

9. Dunnington GL, De Meester TR. Outcome effect of adherence to operative principles of Nissen fundoplication by multiple surgeon. Am J Surg 1993; 166: 654-59.

10. Luostarinen M. Nissen funduplication for gastro-esophageal reflux disease: long term results. Ann Chir Gynaec 1995; 84: 115-20.

11. Oddsdottir M. Minimal access surgery. Surg Clin N Am 2000; 80: 1243-52.

12. Terry M, Smith CD, Branum GD, Galloway K, Waring JP, Hunter JG. Outcomes of laparoscopic fundoplication for gastroesophageal reflux disease and paraesophageal hernia. Experience with 1000 cases. Surg Endosc 2001; 15: 691-9.

13. Bais JE, Bartelsman JF, Bonjer HJ, Cuesta MA, Go PM, KlinkenbergKnol EC, et al. Laparoscopic or conventional Nissen fundoplication for gastro-oesophageal reflux disease: randomised clinical trial. The Netherlands Antireflux Surgery Study Group. Lancet 2000; 355: 170-4.

14. Bowrey DJ, Peters JH. Minimal access surgery. Laparoscopic esophageal surgery. Surg C N Am 2000; 80: 1213-42.

15. Nilsson G, Larsson S, Johnsson F. Randomized clinical trial of laparoscopic versus open fundoplication: evaluation of psychological well-being and changes in everyday life from a patient perspective. Scand J Gastroenterol 2002; 37: 385-91.

16. Frantzides CT, Carlson MA, Madan AK, Stewart ET, Smith C. Selective use of esophageal manometry and 24-Hour $\mathrm{pH}$ monitoring before laparoscopic fundoplication. J Am Coll Surg 2003; 197: 358-63.

17. Streets CG, DeMeester TR. Ambulatory 24-hour esophageal pH monitoring: why, when, and what to do. J Clin Gastroenterol 2003; 37 : 14-22.

18. Gomez R, Seoane J, Moreno D, Cuenca B, Hidalgo M, García A, et al. Manometric changes induced by antireflux surgery (Nissen) and its relation to $\mathrm{pH}$ measurement and clinical findings. An analysis 6 months after the intervention. Rev Esp Enferm Dig 1992; 82: 1-6.

19. Dallemagne B, Weerts C, Jehaes C, Markiewicz S. Causes of failure of laparoscopic antireflux operations. Surg Endosc 1996; 10: 305-10.

20. Watson DI, Jamieson GG, Mitchell PC, Devitt PG, Britten-Jones R. Stenosis of the esophageal hiatus following laparoscopic fundoplication. Arch Surg 1995; 130: 1014-6.

21. Stein HJ, Bremner RM, Jamieson J, D Meester TR. Effect of Nissen fundoplication on esophageal motor function. Arch Surg 1992; 127: 788-90.

22. Martínez de Haro L, Parrilla Paricio P, Ortiz Escandell MA, Morales Cuenca G, Videla Troncoso D, Cifuentes Tebar J, et al. Antireflux mechanism of Nissen fundoplication. A manometric study. Scand J Gastroent 1992; 27: 417-20.

23. Braigrie RJ, Watson DI, Myers JC, Jamieson GG. Outcome of laparoscopic Nissen fundoplication in patients with disordered preoperative peristalsis. Gut 1997; 40: 381-5.

24. Vassilakis JS, Xynos E, Kasapidis P, Chrysos E, Mantides A, Nicolopoulos N. The effect of floppy Nissen fundoplication on esophageal and gastric motility in gastroesophageal reflux. Surg Gynecol Obstet 1993; 177: 608-16.

25. Soto Beauregard C, Baoquan Q, Diez Pardo J, Tovar Larrucea JA. Manometric study of the effects of experimental fundoplication in rats. Rev Esp Enferm Dig 1998; 90: 487-98.

26. Luostarinen M, Isolauri J, Laitinen J, Koskinen M, Keyrilainen O, Markkula H, et al. Fate of Nissen funduplication after 20 years. A clinical, endoscopical and functional analysis. Gut 1993; 34: 1015-20. 
27. Wenner J, Nilsson G, Oberg S, Melin T, Larsson S, Johnsson F. Short-term outcome after laparoscopic and open 360 degrees fundoplication. A prospective randomized trial. Surg Endosc 2001; 15: 1124-8.

28. Apelgren K. Hospital charges for Nissen funduplication and other laparoscopic procedures. Surg Endosc 1996; 10: 359-60.

29. Martínez de Haro LF, Ortiz A, Parrilla P, García Marcilla JA, Aguayo JL, Morales G. Long-term results of Nissen fundoplication in reflux esophagitis without strictures. Clinical, endoscopic, and pH-metric evaluation. Dig Dis Sci 1992; 37: 523-7.
30. Luostarinen $\mathrm{M}$, Virtanen $\mathrm{J}$, Koskinen $\mathrm{M}$, Matikainen M, Isolauri J. Dysphagia and oesophageal clearance after laparoscopic versus open Nissen fundoplication. A randomized, prospective trial. Scand J Gastroenterol 2001; 36: 565-71.

31. Herron DM, Swanstrom LL, Ramzi N, Hansen PD. Factors predictive of dysphagia after laparoscopic Nissen fundoplication. Surg Endosc 1999; 13: 1180-3.

32. Horgan S, Pohl D, Bogetti D, Eubanks T, Pellegrini C. Failed antireflux surgery: what have we learned from reoperations? Arch Surg 1999; 134: 809-15. 